\title{
Surgical treatment of lung cancer in patients under 45 years of age
}

\author{
K. Pawelczyk, M. Marciniak, G. Kacprzak, J. Kolodziej
}

ABSTRACT: Surgical treatment of lung cancer in patients under 45 years of age. K. Pawelczyk, M. Marciniak, G. Kacprzak, J. Kolodziej.

Aim. The aim of the study was to evaluate the characteristics and prognosis of radical surgical treatment in young patients under the age of $\mathbf{4 5}$ with lung cancer.

Methods. We retrospectively analysed the data of $\mathbf{8 5}$ young patients and 211 older patients who underwent anatomical lung resections in Wroclaw Thoracic Surgery Centre.

Results. Less lobectomies were performed ( $\mathrm{p}=\mathbf{0 . 0 4 8})$, the incidence of carcinoid was significantly higher $(p<0.0001)$, stage I of lung cancer was observed less fre- quently $(p=0.023)$, the frequency of metastasis to subcarinal lymph nodes was higher $(\mathrm{p}=\mathbf{0 . 0 0 7})$, a bronchial stump was microscopically infiltrated more frequently, the complete resection was noted rarer $(p=0.016)$ and 3-year survival rate of squamous cell carcinoma patients was worse in younger group $(p=0.017)$. The statistical significance was not observed between the frequency of recurrences and overall survival.

Conclusions. Lung cancer in younger patients seems to be more advanced at the time of surgery. It is probable that the group of younger patients with squamous cell carcinoma will require additional treatment after surgery. Monaldi Arch Chest Dis 2006; 65: 4, 204-209.

Keywords: Lung cancer, surgical treatment, age.

Wroclaw Thoracic Surgery Centre; Wroclaw Medical University - Department of Thoracic Surgery; Wroclaw, Poland.

Correspondence: Konrad Pawelczyk; Wroclaw Thoracic Surgery Centre; Ul. Grabiszynska 105, 53-439 Wroclaw, Poland; e-mail: kopaw@wp.pl

\section{Introduction}

Most lung cancer cases are detected between the fifth and eighth decade of life. However, it is our impression that the age of the diagnosed patients owing to improvement in the diagnosis seems to be decreasing $[1,2,3]$. There is still controversial data regarding the course and prognosis of the disease in younger patients. Some reports suggest that young age predisposes to worse prognosis comparing with the older age $[4,5]$. However, in the other studies the age of the patient has no influence on the course and survival in lung cancer $[6,7,8]$. The different results are explained, among others, by comparing groups of patients with heterogenous treatment modalities. Regarding previous studies we have found that there are only a few reports comparing characteristics and long time survival after surgical treatment with the intention of radical therapy in young and older patients. This study was performed to analyse various characteristics and prognosis after surgery in both groups of patients.

\section{Material and methods}

We analysed the data of 334 patients with lung cancer who underwent pulmonary resection between January 1997 and December 2002 in Wroclaw Thoracic Surgery Centre. 296 of them underwent anatomical pulmonary resection (lobectomy, bilobectomy or pneumonectomy) with an intention of radical, curative therapy and they enrolled the study. We excluded 38 patients who underwent wedge resections or diagnostic/exploratory thoracotomies and those with clinical, non-resective IV stage of the disease before the operation.

In evaluated population 211 patients were over 45 years of age and 85 were $\leq 45$ years at the time of surgery. In most of the previous reports the age considered as "young" ranged between 40 and 50 years. In our study, an upper age limit of 45 years was established. In pre-operative evaluation we routinely performed chest $\mathrm{x}$-rays, computed tomography and bronchoscopy. Positron emission tomography scanning was not available. To determinate pre-operative diagnosis a transthoracic needle aspiration biopsy was performed when it was possible. Mediastinoscopy was routinely performed only in patients with enlarged $(>1 \mathrm{~cm}$ in diameter) lymph nodes detected in CT scans. Patients with $\mathrm{N} 2$ disease received two or three cycles of neoadiuvant chemotherapy. During the 5-year period of the study the surgical technique has not changed. The surgical approach was both by anterolateral and posterolateral thoracotomy in fourth or fifth intercostal space. The bronchial stump was sutured manually using the Sweat or Overholt method and covered with pericardial fat or pleural flap. Mediastinal systematic lymph node dissection was performed routinely and a pathologic diagnosis of lung cancer was confirmed in all cases. The patients with nodal involvement classified as a N2 disease received adjuvant radiotherapy of medi- 
astinum with $50 \mathrm{~Gy}$ and patients with tumour T4 received radiotherapy of tumor bed with $50 \mathrm{~Gy}$.

The follow up based on the regular control of patients after 1,3 and at least every 6 months after the surgery. During control visits chest roentgenograms were performed routinely and computed tomography of the chest or abdomen, abdominal ultrasonography and bronchofiberoscopy in cases when a recurrence of the disease was suspected. The evidence of a tumour within the operated hemithorax (including ipsilateral lymph nodes and bronchial stump) was defined as a presence of local recurrence. Distant metastases were defined as a presence of the disease wherever outside the operated hemithorax. Staging was carried out according to revised in 1997 TNM system.

For statistical purposes $\chi^{2}$ test, Students' $t$ test and non parametric test of Wald-Wolfowitz were used. A $p$ value $<0.05$ was considered to be statistically significant. Survival rates were calculated using the Kaplan-Meier method and compared by log-rank test and Wilcoxon test.

\section{Results}

The average age of the young patients $(\leq 45$ years of age) was 42.1 years (ranging from 30 to 45 years) and 60.5 years (46-76 years) in older patients. Within the group of younger patients more were female $33 / 85$ (38.8\%) compared to the group of the older patients 54/211 $(25.6 \%)(p=0.024)$.
Regarding histological subtype of lung cancer only carcinoid occurred more frequently in younger patients $(12.9 \%$ vs. $0.5 \%, \mathrm{p}<0.0001)$. There was no statistical difference between the incidence of adenocarcinoma $(28.2 \%$ vs. $31.7 \%, \mathrm{p}=0.181)$ or squamous cell carcinoma (41.1\% vs. $49.7 \%$, $\mathrm{p}=0.553$ ) in young and older group. A lobectomy was performed rarer in patients $\leq 45$ years of age $(p=0.046)$ when compared with other anatomical resections. 41 patients underwent lobectomy (48.2\%), 6 bilobectomy (7\%) and 38 pneumonectomy $(44.7 \%)$ in the young group and 134 $(63.5 \%), 8(3.8 \%)$ and $69(32.7 \%)$ respectively in the older group. The evaluation of pathologic TNM revealed that the occurrence of stage I differed significantly in both groups (tab. 1). This stage of the disease was observed more rarely in younger group ( $48.2 \%$ vs. $62.7 \%, \mathrm{p}=0.023$ ). Regarding metastatic lymph nodes we found that subcarinal lymph nodes (group nr. 7) were significantly more frequently affected in younger patients ( $20 \%$ vs. $8.6 \%, p=0.007)$. Statistical importance was not observed in case of other lymph node stations (tab. 2). We found no statistical significance between invasion of lymph node capsule and the number of metastatic lymph nodes in both groups (28/38 - $73.7 \%$ vs. $47 / 62$ - 75.8\%, p=0.812). In younger patients less complete resections $\left(\mathrm{R}_{\mathrm{o}}\right)$ were performed compared with the older patients (67/85 - 78.8\% vs. 186/208 - 89.4\%, p=0.016). There was no statistically important difference in

Table 1. - Pathologic staging of lung cancer

\begin{tabular}{cccc}
\hline Pathologic staging & $\begin{array}{c}\text { Younger patients } \\
\mathbf{n = 8 5}\end{array}$ & $\begin{array}{c}\text { Older patients } \\
\mathbf{n = 2 1 1}\end{array}$ & p value \\
\hline I & $41 / 48.2 \%$ & $132 / 62.5 \%$ & 0.0227 \\
II & $17 / 20 \%$ & $28 / 13.2 \%$ & NS \\
III & $25 / 29.4 \%$ & $47 / 22.2 \%$ & NS \\
IIIA & $20 / 23.5 \%$ & $40 / 19 \%$ & $\mathrm{NS}$ \\
IIIB & $5 / 5.9 \%$ & $6 / 2.8 \%$ & $\mathrm{NS}$ \\
IV & $2 / 2.4 \%$ & $4 / 1.8 \%$ & $\mathrm{NS}$ \\
T3 & $11 / 12.9 \%$ & $21 / 9.9 \%$ & $\mathrm{NS}$ \\
T4 & $5 / 5.9 \%$ & $6 / 2.8 \%$ & $\mathrm{NS}$ \\
N1 & $12 / 14.1 \%$ & $20 / 9.5 \%$ & $\mathrm{NS}$ \\
N2 & $25 / 29.4 \%$ & $43 / 20.5 \%$ & $\mathrm{NS}$ \\
\hline
\end{tabular}

Table 2. - Pathologic evaluation of metastatic lymph nodes

\begin{tabular}{cccc}
\hline Group of lymph nodes & $\begin{array}{c}\text { Metastatic lymph nodes/ } \\
\text { number of patients (n=85) }\end{array}$ & $\begin{array}{c}\text { Metastatic lymph nodes/ } \\
\text { number of patients (n=208) }\end{array}$ & p value \\
\hline 2 & $2 / 2.3 \%$ & $6 / 2.9 \%$ & NS \\
3 & 0 & $3 / 1.4 \%$ & NS \\
4 & $10 / 11.8 \%$ & $18 / 8.6 \%$ & NS \\
5 & $8 / 9.4 \%$ & $15 / 7.2 \%$ & NS \\
6 & 0 & $1 / 0.5 \%$ & 0.0066 \\
7 & $17 / 20 \%$ & $18 / 8.6 \%$ & NS \\
9 & $1 / 1.2 \%$ & $5 / 2.4 \%$ & NS \\
10 & $3 / 3.5 \%$ & $3 / 1.4 \%$ & NS \\
11 & $16 / 18.8 \%$ & $34 / 16.3 \%$ & NS \\
\hline
\end{tabular}


our study between induction/neoadjuvant or adjuvant treatment in both groups (tab. 3). Data regarding postoperative course revealed medium time of hospitalisation to be shorter in patients $\leq 45$ years of age when a lobectomy was performed $(\mathrm{p}=0.005)$ (tab. 4). A statistically important difference was found when considering late complications (>30 days) after the surgery. These occurred more frequently in younger patients $(p=0.032)$ (tab. 5). Post-operative mortality ( $<30$ days) of $2.3 \%(2 / 85)$ was noted in group $\leq 45$ years of age comparing with $5.2 \%(11 / 211)$ in older patients. No statistical significance was found between numbers of local or distant recurrences in both groups (tab. 6). However, local recurrences appeared earlier in young patients (mean 8.8 months, ranged from 2 to 23 months) than in older group (19.8 months, 3-32 months). Similarly, distant recurrences occurred earlier in young patients (mean 11.2 months, $2-60$ months vs. 17.3 ; $1-53$ months in older group).

Follow-up ranged from 3 to 88 months (mean 28.2 ) in the group of young patients and from 2 to
84 months (mean 53.5) in the older group. The 1-, 3 - and 5-year overall survival rates were $77.8 \%$, $52 \%$ and $38.7 \%$ in younger patients and $86 \%$, $68.2 \%$ and $48.1 \%$ in older patients. The KaplanMeier curves for overall survival in young and older patients are shown at (fig. 1). Survival analysis by stage of the disease did not reveal any statistically important differences in both groups (tab. 7). However, the medium survival in younger patients was shorter in each stage of the disease and amount to $36.1,27.3$ and 21.7 months in I, II and III stage comparing with $58.1 ; 50.1$ and 40.4 months in older patients, respectively. The overall median survival time was shorter in the younger group (29.7 months vs. 52.2 months in older group) but it was not significantly different. In the 1-, 3- and 5-year survival of patients with complete resection $\left(R_{0}\right)$ there was no significant difference between the two groups although it seems that younger patients live for a shorter period of time (79.2\%; 62.5\%; $45.8 \%$ vs.85.4\%; 70.9\%; $51.2 \%$, respectively). Survival was also analysed by histological subtype of lung cancer in both groups. The

Table 3. - Evaluation of pre- and postoperative additional treatment in both groups

\begin{tabular}{lccc}
\hline Pre- and postoperative therapy & $\begin{array}{c}\text { Younger patients } \\
\mathbf{n = 7 0}\end{array}$ & $\begin{array}{c}\text { Older patients } \\
\mathbf{n = 1 1 9}\end{array}$ & p value \\
\hline Adiuvant chemotherapy & $18 / 25.7 \%$ & $44 / 37 \%$ & $\mathrm{NS}$ \\
Adiuvant radiotherapy & $10 / 14.3 \%$ & $11 / 9.2 \%$ & $\mathrm{NS}$ \\
Adiuvant chemoradiotherapy & $11 / 15.7 \%$ & $13 / 10.9 \%$ & $\mathrm{NS}$ \\
Neoadiuvant/induction therapy & $39 / 9.4 \%$ & $68 / 6.2 \%$ & $\mathrm{NS}$ \\
\hline
\end{tabular}

Table 4. - Medium time of hospitalization

\begin{tabular}{lccc}
\hline Type of procedure & $\begin{array}{c}\text { Younger patients } \\
\text { (range of hospitalization/days) } \\
\text { medium }\end{array}$ & $\begin{array}{c}\text { Older patients } \\
\text { (range of hospitalization/days) } \\
\text { medium }\end{array}$ & p value \\
\hline Lobectomy & $(6-15) 9.2$ & $(5-60) 11.1$ & 0.0054 \\
Pneumonectomy & $(5-19) 11.9$ & $(5-45) 11.7$ & NS \\
Bilobectomy & $(8-60) 21$ & $(6-30) 14.6$ & NS \\
\hline
\end{tabular}

Table 5. - Postoperative early and late complications

\begin{tabular}{lcc}
\hline Complications & $\begin{array}{c}\text { Younger patients } \\
\mathbf{n = 8 5}\end{array}$ & $\begin{array}{c}\text { Older patients } \\
\mathbf{n = 2 1 1}\end{array}$ \\
\hline Early (<30 days) & $13 / 15.3 \%$ & $43 / 20.4 \%$ \\
\hline Air leak $>7$ days & $2 / 2.4 \%$ & $5 / 2.4 \%$ \\
Redreinage & $5 / 5.9 \%$ & $20 / 9.5 \%$ \\
Empyema & $1 / 1.2 \%$ & $5 / 2.4 \%$ \\
Wound infection & $1 / 1.2 \%$ & $4 / 1.9 \%$ \\
Vascular and cardiologic & $1 / 1.2 \%$ & $6 / 2.8 \%$ \\
Rethoracotomy & 0 & $3 / 1.4 \%$ \\
\hline Late (>30days) & $5 / 5.9 \%$ & $3 / 1.4 \%$ \\
\hline Empyema & $4 / 4.7 \%$ & $3 / 1.4 \%$ \\
Pneumothorax & $1 / 1.2 \%$ & 0
\end{tabular}


Table 6. - Evaluation of local and distant recurrences

\begin{tabular}{lccc}
\hline Recurrences & $\begin{array}{c}\text { Younger patients } \\
\mathbf{n = 2 5}\end{array}$ & $\begin{array}{c}\text { Older patients } \\
\mathbf{n = 4 8}\end{array}$ & p value \\
\hline Local & $6 / 24 \%$ & $6 / 12.5 \%$ & NS \\
\hline Distant & $19 / 76 \%$ & $42 / 87.5 \%$ & NS \\
\hline Brain & $9 / 47.4 \%$ & $15 / 35.7 \%$ & $\mathrm{NS}$ \\
Bones & $1 / 5.3 \%$ & $9 / 21.4 \%$ & $\mathrm{NS}$ \\
Second lung & $5 / 26.3 \%$ & $10 / 23.8 \%$ & $\mathrm{NS}$ \\
Soft tissue & $1 / 5.3 \%$ & $1 / 2.4 \%$ & $\mathrm{NS}$ \\
Distant lymph nodes & $2 / 10.5 \%$ & $1 / 2.4 \%$ & $\mathrm{NS}$ \\
Liver & 0 & $5 / 11.9 \%$ & $\mathrm{NS}$ \\
Suprarenal gland & 0 & $1 / 2.4 \%$ & $\mathrm{NS}$ \\
\hline
\end{tabular}

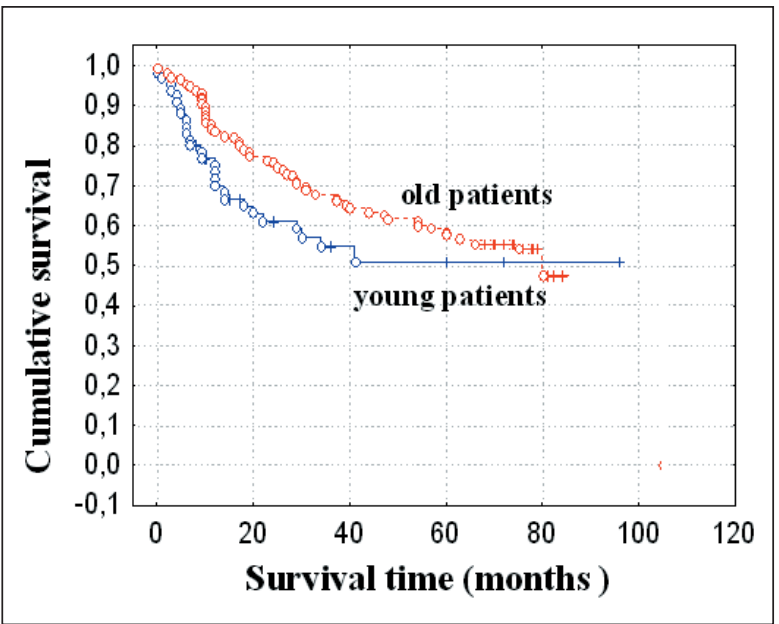

Fig. 1. - The Kaplan-Meier overall survival rates comparing with logrank test $(\mathrm{p}=0.1558)$ and with Wilcoxon test in accordance with Peto and Peto $(\mathrm{p}=0.0782)$ shows no statistically important differences between the survival of young and older patients. statistical significance was noted only in 3- year survival in patients diagnosed with squamous cell carcinoma (47\% in younger group vs. $77.2 \%$ in older group, $\mathrm{p}=0.017$ ) (tab. 7).

\section{Discussion}

Most of the previous studies enrolling surgically treated young patients included heterogeneous groups after different procedures like anatomical, wedge resections or exploratory thoracotomies. In the present study, to evaluate more precisely the prognosis and characteristics of surgical treatment we decided to select a group of patients treated only with a curative intention.

A significant difference between the number of males and females in both groups (male to female ratio in younger 1.6:1 and 2.9:1 in older group) is comparable with recent investigations

Table 7. - 1-, 3- and 5-year survival according to TNM status and subtype of lung cancer

\begin{tabular}{|c|c|c|c|c|}
\hline & Survival & Younger patients & Older patients & $p$ value \\
\hline \multirow[t]{3}{*}{ I stage } & 1 year & $28 / 31-90.3 \%$ & $62 / 71-87.3 \%$ & NS \\
\hline & 3 years & $16 / 22-72.7 \%$ & $55 / 71-77.5 \%$ & NS \\
\hline & 5 years & $8 / 14-57.1 \%$ & $48 / 88-54.5 \%$ & NS \\
\hline \multirow[t]{3}{*}{ II stage } & 1 year & $11 / 15-73.3 \%$ & $11 / 14-78.6 \%$ & NS \\
\hline & 3 years & $5 / 12-41.7 \%$ & $8 / 14-57.1 \%$ & NS \\
\hline & 5 years & $2 / 6-33.3 \%$ & $7 / 14-50 \%$ & NS \\
\hline \multirow[t]{3}{*}{ III stage } & 1 year & $10 / 18-55.5 \%$ & $17 / 23-73.9 \%$ & NS \\
\hline & 3 years & $5 / 18-27.8 \%$ & $10 / 23-43.5 \%$ & NS \\
\hline & 5 years & $2 / 16-12.5 \%$ & $8 / 30-26.7 \%$ & NS \\
\hline \multirow[t]{3}{*}{ IIIA stage } & 1 year & $10 / 16-62.5 \%$ & $15 / 21-71.4 \%$ & NS \\
\hline & 3 years & $5 / 16-31.2 \%$ & $9 / 21-42.8 \%$ & NS \\
\hline & 5 years & $2 / 14-14.3 \%$ & $7 / 27-25.9 \%$ & NS \\
\hline \multirow[t]{3}{*}{ Adenocarcinoma } & 1 year & $16 / 19-84.2 \%$ & $27 / 32-84.4 \%$ & NS \\
\hline & 3 years & $9 / 17-52.9 \%$ & $21 / 32-65.6 \%$ & NS \\
\hline & 5 years & $3 / 8-37.5 \%$ & $16 / 39-41 \%$ & NS \\
\hline \multirow[t]{3}{*}{ Aquamous cell carcinoma } & 1 year & $15 / 20-75 \%$ & $49 / 57-86 \%$ & NS \\
\hline & 3 years & $8 / 17-47 \%$ & $44 / 57-77.2 \%$ & 0,0171 \\
\hline & 5 years & $5 / 13-38.5 \%$ & $41 / 70-58.6 \%$ & NS \\
\hline
\end{tabular}


and is probably connected with increasing smoking habits in the young female population $[7,9$, $10]$.

Regarding data of pathologic findings we found that only the presence of carcinoid was significantly higher in younger group which is similar to earlier findings [8].

There were no significantly higher incidences of other subtypes of lung cancer in both groups. In particular, the status of adenocarcinoma, which is described in many previous studies $[9,10,11]$ as a predominant type in younger patients, is different in our investigation $(28.2 \%$ in younger vs. $31.7 \%$ in older group). As a possible reason we suggest more advanced clinical stages (IIIB, IV) of this aggressive subtype in younger patients which disqualified them from radical surgical intervention.

In our study, pathologic stage I of lung cancer was noted to be significantly rarer in younger patients. Less patients in the lowest stadium of the disease led to presume they were in the more advanced stage of the disease in the group $\leq 45$ years of age at the time of operation. The studies enrolling patients with all stages of the disease (operable and non-operable) point at more advanced stages of lung cancer at the time of diagnosis in younger population $[4,7,12,13]$. We performed less lobectomies $(p<0.05)$ and more extensive surgical procedures like bilobectomy or pneumonectomy in younger patients what can additionally confirmed locally more advanced disease in this population. These results are comparable with study of Tian and al. [14]. Higher incidence of more advanced disease in younger individuals could be probably explained by stronger motivation of surgeon to qualified and performed curative surgical treatment regarding "young" age of the patient. A higher frequency of surgically treated young patients comparing with the older group is also described in the literature $[9,15]$.

Pathologic evaluation of lymph node status in both groups revealed significantly higher incidence of metastasis to subcarinal station in younger patients. As is well known, the involvement of subcarinal lymph nodes is regarded as a negative prognostic factor in many reports $[16,17$, 18]. In our series mediastinoscopy was routinely performed only in patients with enlarged $(>1 \mathrm{~cm}$ in diameter) lymph nodes detected in CT scans. The high incidence of subcarinal lymph nodes involvement was present without enlargement of these lymph nodes. It is probable that the routine mediastinoscopy will be indicated in younger patients especially when PET scan is not available in each case. The other factor associated with poor prognosis, capsular lymph node invasion [18], was not significantly different in both groups.

Statistically significant lower rate of complete resections $\left(\mathrm{R}_{\mathrm{o}}\right)$ noted in patients $\leq 45$ years of age compared with older patients is further evidence to suggest more advanced disease. Within the group of young patients $12(14.1 \%)$ had a microscopically infiltrated bronchial stump $\left(\mathrm{R}_{1}\right)$ compared to $8.2 \%$ in the older group $(p=0.7268)$. The bronchial stump was not routinely examined during the op- eration in our centre, only in the case of macroscopical suspicion of infiltration. The lower rate of complete resection is observed in other reports, however they also enrolled patients with non-curative resections (e.g. wedge resections, exploratory thoracotomies) $[12,19]$. Although lung cancer was more advanced after pathologic evaluation in younger group, no statistically significant correlation was observed between the application of induction/neoadiuvant or adjuvant treatment.

Evaluation of post-operative course of the disease revealed a significantly shorter time of hospitalisation in case of lobectomy and lower overall, post-operative mortality ( $<30$ days) in younger group. No statistically important correlation was noted between early complications ( $<30$ days) in both groups. Nevertheless, in younger patients less redrainages $(5.9 \%$ vs. $9.5 \%)$ and heart/vascular complications (1.2\% vs. $3.3 \%)$ were observed compared with the older group. A slightly higher incidence of late complications ( $>30$ days) was noted in group $\leq 45$ years of age. Shorter duration of hospitalisation and lower mortality in younger patients seems to be clear, the reason of higher rate of late post-operative complications in this group remains obscure. Unfortunately, looking through the MEDLINE Database we were unable to find investigations which confront this kind of data.

In addition we were also unsuccessful in our attempt to find any published literature with data comparing incidence of recurrences in young and older people after surgically treated lung cancer. In our study no significant difference in the number of local and distant recurrences in two groups was observed. However, a faster appearance of local and distant recurrences (8.8 vs. 19.8 months and 11.2 vs. 17.3 months, respectively) seems to evidence a need for a more aggressive disease in younger patients. A higher risk of lung cancer recurrence after surgical treatment in patients $\leq 45$ years of age doesn't entail significantly worse survival in younger patients. The Kaplan-Meier survival curves did not show significant differences in survival between two groups. 3-year survival was shorter in younger patients with squamous cell carcinoma (SCC) $(\mathrm{p}=0.017)$. It is not excluded that 5years survival could be also significantly worse in younger group with SCC if older patients didn't die from other reasons (connected with old age, not with recurrence of the disease).

Overall 1-, 3- and 5-year survival in younger group and survival in consecutive stages of lung cancer as well, however slightly lower, are not of significant importance. Similarly, statistically important differences were not observed when compared 1-, 3- and 5-year survival in young and older patients with adenocarcinoma or after complete resections $\left(\mathrm{R}_{\mathrm{o}}\right)$. These results are comparable with other studies $[6,12,19,20]$.

Unfortunately this study is not prospective so our results should be carefully interpreted. The second limitation of the study proved to be the difficulties associated with the collection of follow up data, particularly regarding the incidence of recurrences. 
According to our experience, lung cancer is more advanced at the time of surgery in patients $\leq 45$ years of age and we are favourable to the opinion that the disease seems to be more aggressive in this population. Nevertheless, overall survival in two groups is not significantly different. Only in case of squamous cell carcinoma does the medium-term survival in younger patients seem to be significantly worse when compared with older population. Probably this group of patients may require additional treatment before or after the surgery but further studies are necessary. An intraoperative histopathological evaluation of bronchial stump in the young group should be performed even in cases of no macroscopical invasion to avoid incomplete resection.

\section{References}

1. Nugent WC, Edney BA, Hammerness PG, et al. NonSmall Cell Lung Cancer at the Extremes of Age: Impact on Diagnosis and Treatment. Ann Thorac Surg 1997; 63: 193-197.

2. Jemal A, Cokkinides VE, Shafey O, et al. Lung cancer trends in young adults: an early indicator of progress in tobacco control (United States). Cancer Causes Control 2003; 14: 579-585.

3. Tyczynski JE, Bray F, Aareleid T, et al. Lung cancer mortality patterns in selected Central, Eastern and Southern European countries. Int J Cancer 2004; 109 : 598-610.

4. Antkowiak JG, Regal AM, Takita H. Bronchogenic carcinoma in patients under age 40. Ann Thorac Surg 1989; 47: 391-393.

5. Bourke W, Milstein D, Giura R, et al. Lung cancer in young adluts. Chest 1992; 102: 1723-1729.

6. Sugio K, Ishida T, Kaneko S et al. Surgically resected lung cancer in young adults. Ann Thorac Surg 1992; 53: 127-131.

7. Ramalingam S, Pawlish K, Gadgeel S, et al. Lung cancer in young patients: analysis of a Surveillance, Epi- demiology and End Results database. J Clin Oncol 1998; 16: 651-657.

8. Andou A, Shimizu N, Maruyama S, et al. Study on cases of resected primary lung cancer in young persons. Kyobu Geka 1992; 45: 379-383.

9. Schonfeld N, Lienert T, Serke M, et al. Bronchial carcinoma in young adults. Pneumologie 1999; 53: 480484.

10. Maruyama R, Yoshino I, Yohena T, et al. Lung cancer in patients younger than 40 years of age. J Surg Oncol 2001; 77: 208-212.

11. Riquet M, Medioni J, Manac'h, et al. Non-small cell lung cancer: surgical trends as a function of age. Rev Mal Respir 2001; 18: 173-184.

12. Icard P, Regnard JF, de Napoli S, et al. Primary lung cancer in young patients: a study of 82 surgically treated patients. Ann Thorac Surg 1992; 54: 99-103.

13. Whooley BP, Urschel JD, Antkowiak JG, et al. Bronchgenic carcinoma in young patients. J Surg Oncol 1999; 71: 29-31.

14. Tian DL, Liu HX, Zhang L, et al. Surgery for young patients with lung cancer. Lung Cancer 2003; 42: 215220.

15. Awadh-Behbehani N, Al-Humood K, Ayed A, et al. Comparison between young and old patients with bronchogenic carcinoma. Acta Oncol 2000; 39: 995-999.

16. Okada M, Tsubota N, Yoshimura M, et al. Prognosis of completely resected pN2 non-small cell lung carcinomas: What is the significant node that affects survival? J Thorac Cardiovasc Surg 1999; 118: 270-275.

17. Watanabe Y, Hayashi Y, Shimizu J, et al. Mediastinal nodal involvement and the prognosis of non-small cell lung cancer. Chest 1991; 100: 422-428.

18. Orlowski TM, Szczesny TJ. Surgical treatment of stage III non-small cell lung cancer. Lung Cancer 2001; 34 Suppl 2: S137-143.

19. Shimono T, Hayashi T, Kimura M, et al. Surgical treatment of primary lung cancer in patients less than 40 years of age. J Clin Oncol 1994; 12: 981-985.

20. Bernet F, Brodbeck R, Guenin MO, et al. Age does not influence early and late tumor-related outcome for bronchogenic carcinoma. Ann Thorac Surg 2000; 69: 913-918.

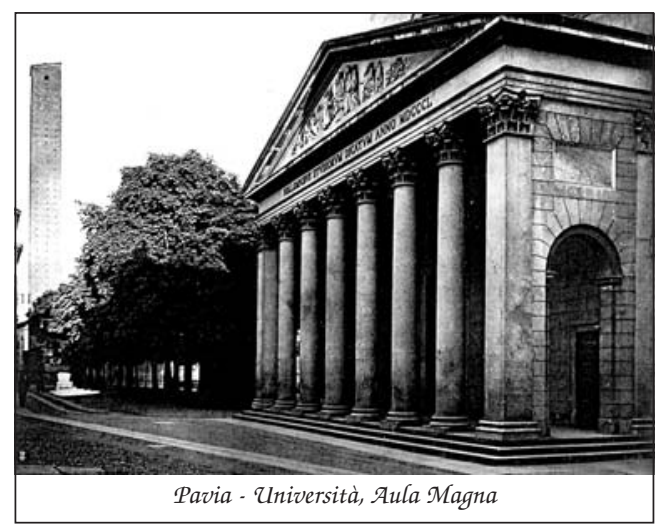

